\title{
Design and Fabrication of a Portable Tubular Filter Pipe for Borehole Water Purification Systems
}

\author{
Yousuo Digieneni", Orlando Ketebu, Farrow Timipere Salome \\ Department of Chemical Engineering, Niger Delta University, Yenagoa, Nigeria \\ Email address: \\ digieneniyousuo@yahoo.com (Y. Digieneni), orlandok2@yahoo.com (O. Ketebu), salomefarrow@ndu.edu.ng (F. T. Salome) \\ ${ }^{*}$ Corresponding author
}

\section{To cite this article:}

Yousuo Digieneni, Orlando Ketebu, Farrow Timipere Salome. Design and Fabrication of a Portable Tubular Filter Pipe for Borehole Water Purification Systems. American Journal of Chemical Engineering. Vol. 7, No. 5, 2019, pp. 120-129. doi: 10.11648/j.ajche.20190705.11

Received: October 11, 2019; Accepted: October 29, 2019; Published: November 5, 2019

\begin{abstract}
Two main sources of water (the surface water and underground water) were briefly discussed in this paper. Filtration which is a very significant treatment process for both surface water and underground water was also discussed. A portable tubular filter pipe for borehole water purification system was designed and fabricated. The materials used in the portable tubular filter pipe (sand layer depth of $0.15 \mathrm{~m}$ of size $0.8-2 \mathrm{~mm}$ and coarse gravel layer depth of $0.02 \mathrm{~m}$ of size 5 $8 \mathrm{~mm}$ ) were sourced locally. The coarse aggregate (gravel) layer served as support and distribution of water while the sand layer served as the filter medium. The diameter of the portable tubular filter pipe was assumed to take 4 inches PVC diameter pipe $(0.1016 \mathrm{~m})$. The design reveals that the filter area is $0.0479 \mathrm{~m}^{2}$, the flowrate in the filter is $8 \times 10^{-5} \mathrm{~m}^{3} / \mathrm{s}$, the filter volume is $0.02 \mathrm{~m}^{3}$ and the headloss in the filter is $0.5 \mathrm{~m}$. Materials used for the fabrication of the portable tubular filter pipe are PVC materials that are easily available in water treatment stores. Tests were carried with the fabricated portable tubular filter pipe on borehole water. The results show that the portable tubular filter pipe performed relatively well in purifying borehole water.
\end{abstract}

Keywords: Design, Fabrication, Tubular, Borehole, Purification

\section{Introduction}

The work [21] stated that Water $\left(\mathrm{H}_{2} \mathrm{O}\right)$ which is a chemical compound formed from Hydrogen and oxygen occupies a major part of the earth crust and is described as a universal solvent and that Living things cannot exist without water. Water actually takes about two-third of the human body and its uses for human life cannot be overemphasized. Amongst the sources of water, two sources of water are very significant-the surface and underground water. Ground water is a major source of borehole water in most regions.

According to many literatures, [2-9, 11, 21], untreated water contains many impurities. Theses impurities consist of suspended particles (fine silts and clays), biological matter (bacteria, plankton, spores, cysts or other matter) and floc. Some of the dissolved impurities or substances (like Iron, Manganese, etc) in the water may result to bad taste, odour, turbidity, colour, hardness, and excessive carbon dioxide, corroding concrete and metal parts in the distribution system. As a result, many researchers, [6, 12, 21] are currently working on the physiochemical qualities of borehole and spring water, the impurities of borehole water and the potential health risk to rural communities.

The aim of this work is to design and fabricate a portable tubular filter pipe for water purification system, especially for boreholes. Figure 1 shows a typical borehole water purification system. The raw water from the ground (borehole) is taken by a water pump (submersible or surface) and it is sent to the open tank (aeration/Sedimentation tank) through the open air for oxidation of iron and manganese. The water found in the open tank is toxic and contaminated as it is untreated. The untreated water from the open tank is sent to the treatment tank by gravity fall. The treatment tank contains sand, activated carbon and gravel in layers from the top to the bottom. The treatment tank is also chlorinated for further disinfection. Valves are attached at various points to control flow rate and direction. The efficiency in choosing the treatment techniques depends on the efficiency in reducing turbidity (97-99\%), removal of viruses and bacteria (pathogens and protozoa) and other objectionable tasks and odor. Figure 2 shows the possible positions of the proposed portable tubular filter pipe (F). It is either placed immediately after the aeration/sedimentation tank 
for purification of the untreated water from the placed after the treatment tank for further purification. aeration/sedimentation tank before the treatment tank or it is

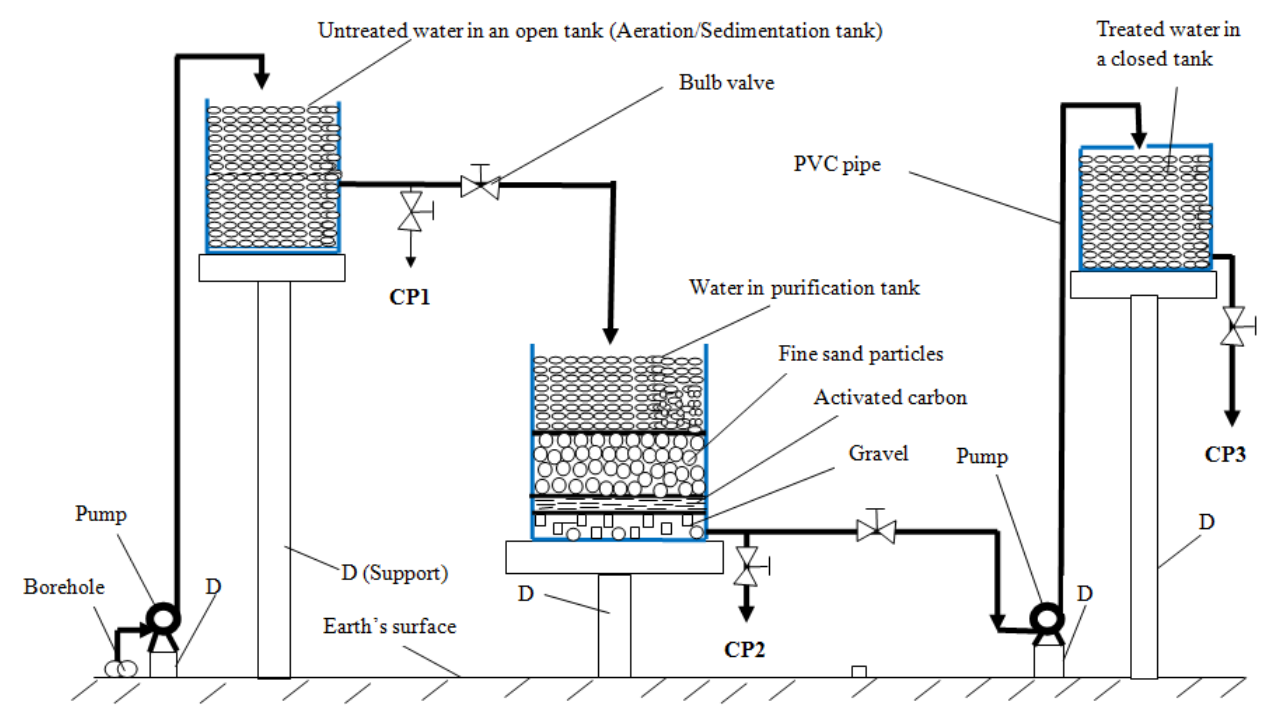

Figure 1. A simplified diagram of a borehole water purification system. CP1, CP2 and CP3 are water collection points. D is a support or stand.

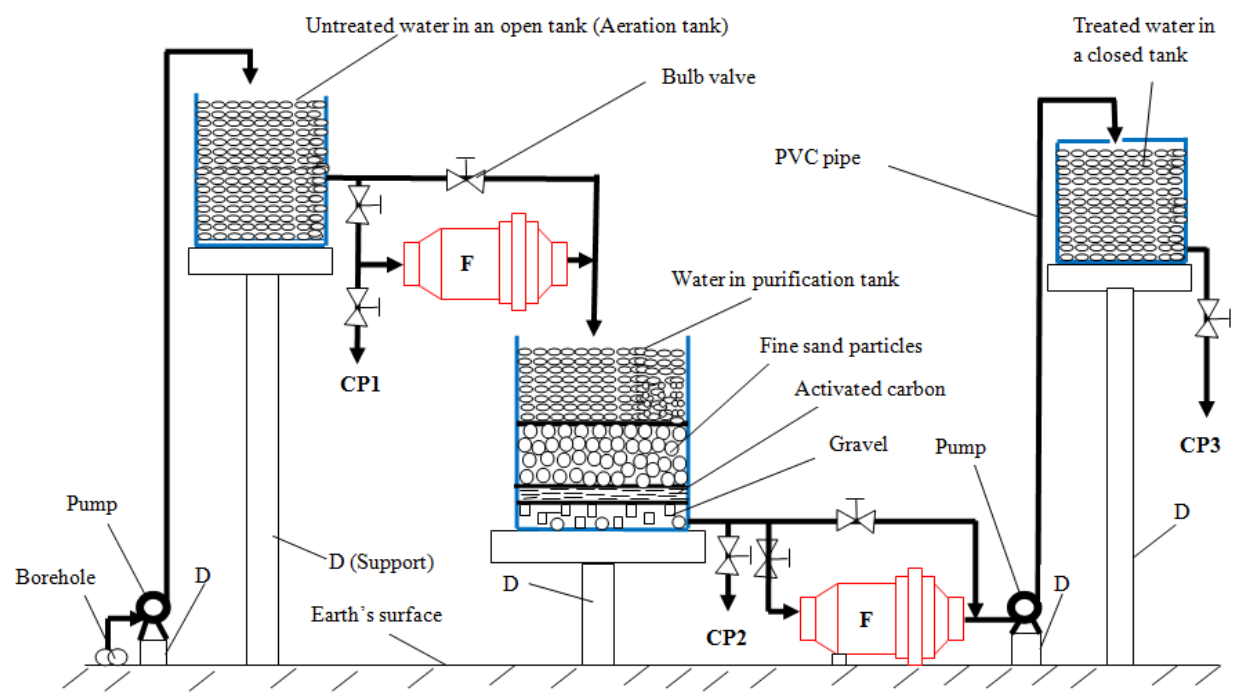

Figure 2. A simplified diagram of a borehole water purification system showing the possible positions of the portable tubular filter pipe (F).

\section{Water Purification System}

Both surface and underground water purification systems have many treatment stages. A typical water treatment processes have been reported elsewhere, [14, 21]. A summary of the treatment stages for both Surface and underground water are shown in figure 3 and Figure 4 respectively. Filtration process is very important for both surface and underground water purification systems and so it is further explained in section 2.1.

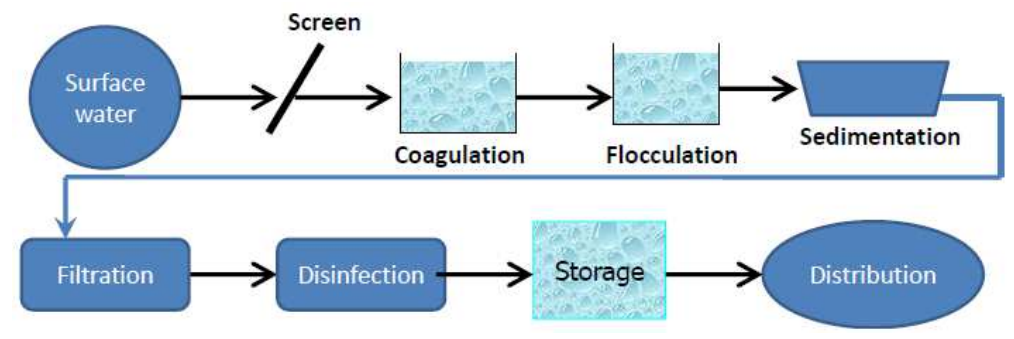

Figure 3. Treatment stages for surface water. 


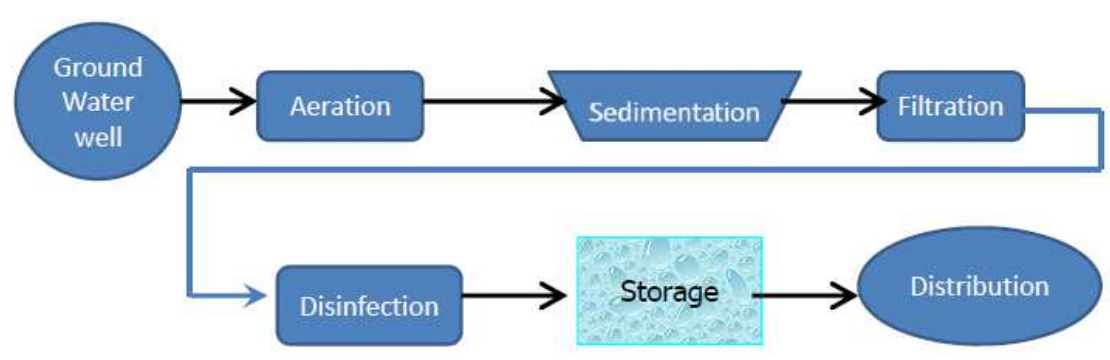

Figure 4. Treatment stages for underground water.

\subsection{Filtration}

Filtration is the process of passing water through material to remove particulate and other impurities, including floc, from the water being treated. The material used in filters for public water supply is normally a bed of sand, coal, or other granular substances like activated carbon. Filtration is a solid-liquid separation process in which the liquid passes through a porous medium to remove as much fine suspended solids as possible. Water or wastewater containing suspended matter is applied to the top of the filter bed. As the water (or wastewater) filters through the porous medium, the suspended matter in the fluid is removed by a variety of mechanisms. These mechanisms are: Straining, Sedimentation, Impaction, Interception, Adhesion, Adsorption, Flocculation, Biological growth [2].

(i) Straining: Particles with pore space of filtering medium are strained out mechanically and also are trapped in filter by chance contact.

(ii) Sedimentation: Particles settle on the filter medium.

(iii) Impaction: Heavy particles will not follow the flow streamlines.

(iv) Interception: Particles moving along in the streamline are removed when they come in contact with the surface of filtering medium.

(v) Adhesion: Flocculants particles become attached to the surface of the filtering medium as they pass by.

(vi) Adsorption (chemical or physical or both): Once a particle has been brought in contact with the surface of the filtering medium or with other particles.

(vii) Flocculation: Large particles overtake smaller particles, join them, and form still larger particles. These are than removed by one or more of the above removal mechanisms.

(viii) Biological growth: Biological growth within the filter will reduce the pore volume and may enhance the removal of particles with any of the above removal mechanisms. Substances collected on the surface of the filter medium and available nutrient will result to organisms begin to grow on the surface of filter. A mat is formed containing slimy "zoogleal" organisms known as "Schmutzdecke". This helps in the straining action of the filter, but must be removed when the headloss through the filter is high. It is undesirable in rapid sand filter because it encourages formation of mud balls during backwashing.

\subsection{Classifications of Filtration}

According to [2], Filtration is classified as follows:

(i) According to actual filtration or backwashing

(a) Actual filtration (process by which the water is cleaned) or

(b) Backwashing (cleaning of filter medium).

(ii) According to deep filtration or not

(a) Deep bed filtration (depth filtration) - Solids are removed within a bed of porous material e.g. Rapid granular bed or

(b) Cake filtration - Particle removal occurs largely at the surface of the media through formation of a filter cake e.g. Pre-coat filtration (diatomite, diatomaceous earth) Slow sand filters

(iii) According to type of granular medium used

(a) Single medium (sand or anthracite)

(b) Dual media (anthracite and sand)

(c) Multimedia (anthracite, sand, garnet)

Dual media filters are better, having longer filtration run and available pore volume is maximum at the top of filter and gradually decreases to a minimum at the bottom of filter.

(iv) According to flow through medium

(a) Gravity filters: They are open to the atmosphere. Flow through the medium is achieved by gravity.

(b) Pressure filters: Filter medium is contained in pressure vessel. Water is delivered to the vessel under pressure.

(v) According to rate of filtration

(a) Rapid sand filters

(b) Slow sand filters

(vi) According to filter flow control scheme

(a) Constant rate (constant head or variable head)

(b) Declining rate (constant head or variable head)

\subsection{Properties of Filter Media}

A number of properties of filter media are important in affecting filtration performance. These are size, size distribution, slope, density and porosity.

\subsubsection{Grain Size and Size Distribution}

The smaller the size of granular media, the smaller the pore openings through which the water must pass. Small pore openings increase filtration efficiency. Uniform granular media will permit deeper penetrations of floc better utilization of the storage capacity of the bed. Moreover; 
during backwashing (cleaning of media with water in reversal direction of flow) bed of non uniform medium will stratify with smaller particles $\rightarrow$ smaller pore openings at the top.

The size of filter media is specified by effective size. The uniformity of filter media is specified by uniformity coefficient. Effective size $\left(\mathrm{d}_{10}\right)$ and Uniformity coefficient $\left(\mathrm{d}_{60} / \mathrm{d}_{10}\right)$ are determined by sieve analysis.

\subsubsection{Grain Shape}

The shape of filter grains is important because it effects

(i) Backwash flow requirement of medium

(ii) Fixed bed porosity

(iii) Headloss for flow through medium

(iv) Filtration efficiency

(v) The ease of sieving

\subsubsection{Sphericity and Porosity}

One useful measure of shape is sphericity $(\psi)[2]$. Sphericity is given by

$$
\psi=\frac{\text { surface area of sphere having same volume with particle/Vs }}{\text { surface area of particle } / \mathrm{Vp}}(1)
$$

Since $\mathrm{Vs}=\mathrm{Vp}$

$$
\psi=\frac{\text { surface area of sphere having same volume with particle }}{\text { surface area of particle }}
$$

This implies that

$$
\frac{A_{p}}{V_{p}}=\frac{6}{\psi d}
$$

(Where s represents sphere and $\mathrm{p}$ is particle, $\mathrm{V}$ is volume, $\mathrm{A}$ is area and $\mathrm{d}$ is diameter). As the particles become less spherical, porosity of a given volume increases. Porosity depends on how well particles fi together. Porosity could be fixed bed porosity (compacted - bed porosity) or Loose bed porosity.

\section{Materials and Method}

\subsection{Reviewed Literatures to the Design of the Portable Tubular Filter Pipe}

In determining the size and the filtration rates of the filter bed, a review of relevant literature from journals, scientific reports, and academic texts on similar research projects was done, $[1,12,13,15-21]$.

\subsection{Assumptions for the Design}

The diameter of the portable tubular pipe is assumed to be the diameter of a 4 inches PVC pipe. The filtration minimum media depth [height] was determined using the Hudson formula to avoid breakthrough of floc as given by [18].

$$
\frac{\mathrm{Qd}^{3} \mathrm{~h}}{\mathrm{~L}}=\mathrm{B}_{\mathrm{i}} \times 29323
$$

Where

$\mathrm{Q}$ - Filtration rate $\left(\mathrm{m}^{3} / \mathrm{m}^{2} / \mathrm{h}\right)$
$\mathrm{L}$ - Depth of filter bed (m)

$\mathrm{h}$ - Terminal head loss (m)

$\mathrm{d}$ - Sand size (mm)

$\mathrm{Bi}$ - Breakthrough index whose value ranges between 0.0004 to 0.006 depending on response to pre-treatment in the filter unit (dimensionless).

The following assumptions were also made to determine the minimum sand bed depth, L:

(i) $\mathrm{Bi}=4 \times 10^{-4}$ for poor response to filtration and average degree of pretreatment and;

(ii) Terminal head loss $=0.25 \mathrm{~m}$ as given by [18].

From the effective sand size determined, the depth was checked against breakthrough of floc by calculating the minimum depth required.

\subsection{Aeration-sedimentation Tank Calculations}

This calculation determines the volume of the aerationsedimentation tank, (V) in order to achieve a retention time, (t) of 30 minutes having a maximum flow rate, (Q) of 16 $1 / \mathrm{min}$.

$$
\begin{gathered}
\mathrm{V}=\mathrm{Q} \times \mathrm{t} \\
\mathrm{V}=16 \times 30=480 \mathrm{~L}=0.48 \mathrm{~m}^{3}
\end{gathered}
$$

Hence, the required size of the aeration-sedimentation tank should be approximately $0.5 \mathrm{~m}^{3}$.

Water from the aeration-sedimentation tank will flow by gravity to the portable tubular filter pipe when full using the valves as appropriate. The filter area has the capacity to accept water flow from the aeration-sedimentation tank as calculated below. The first layer to receive the water is coarse aggregate [gravel] layer with grain size 5-8 $\mathrm{mm}$ with a bed depth of $0.02 \mathrm{~m}$ and the second layer to receive the water is sand layer with grain size $0.8-2 \mathrm{~mm}$ with bed depth $0.15 \mathrm{~m}$ and the third layer is coarse aggregate [gravel] layer with grain size $5-8 \mathrm{~mm}$ with a bed depth of $0.02 \mathrm{~m}$. The water moves by downward flow through the layers from top to bottom by gravity to the outlet tap at the bottom part of the portable tubular filter pipe thus discharging the treated water. The gravel layers at the top $\left(1^{\text {st }}\right.$ layer $)$ and bottom layer $\left(3^{\text {rd }}\right.$ layer) help as support and distribution of water, therefore, the effective filter diameter used in design is that of the sand layer, effective diameter (d) is 4 inches PVC diameter pipe $(0.1016 \mathrm{~m})$.

\subsection{Filter Capacity Calculations}

The flow out from the aeration-sedimentation tank or any pretreatment unit is equal to the flow that enters the Portable tubular filter pipe, therefore,

$$
\begin{gathered}
\mathrm{Q}_{\text {in }}=\mathrm{Q}_{\text {out }} \\
\mathrm{Q}_{\text {in }}=16 \mathrm{l} / \mathrm{min}=0.016 \mathrm{~m}^{3} / \mathrm{min}=2.67 \times 10^{-4} \mathrm{~m}^{3} / \mathrm{s}
\end{gathered}
$$

The formula for flow rate through the filter media which is dependent on the filter:

Area, (A) is given by Darcy's equation [18]: 


$$
Q=\mathrm{k} \times \mathrm{A} \times \mathrm{I}
$$

For vertical flow rate the hydraulic gradient, i, is 1 which gives;

$$
Q=\mathrm{k} \times \mathrm{A} \times 1=\mathrm{k} \times \mathrm{A}
$$

The hydraulic conductivity, $\mathrm{k}$, for sand size ranging between medium and very coarse according to [18] is:

$$
\mathrm{k}_{\text {ave }}=5.00 \times 10^{-3} \mathrm{~m}^{-3} / \mathrm{s}
$$

The hydraulic conductivity is divided by a safety factor of 3 due to clogging of the filter thus giving:

$$
\mathrm{K}_{\mathrm{ave}}=\frac{5.00 \times 10^{-3}}{3} \mathrm{~m} / \mathrm{s}=1.67 \times 10^{-3} \mathrm{~m} / \mathrm{s}
$$

The filter area is tubular and is given by

$$
A=2 \pi r l=2 \pi \frac{D}{2} l
$$

Where, $\mathrm{r}=$ radius, $\mathrm{D}=$ diameter $=0.1016 \mathrm{~m}$ and $1=$ the sand filter depth $=0.15 \mathrm{~m}$

This implies that

$$
\begin{gathered}
A=2 \pi r H=2 \pi \frac{D}{2} h=2 \times 3.1428 \times \frac{0.1016}{2} \times 0.15 \\
=0.0479 \mathrm{~m}^{2}
\end{gathered}
$$

With the filter area, $\mathrm{A}=0.0479 \mathrm{~m}^{2}$ and then using Darcy's equation to calculate the flow rate of the portable tubular filter pipe

$$
Q=k \times \mathrm{A}=1.67 \times 10^{-3} \times 0.0479=8 \times 10^{-5} \mathrm{~m}^{3} / \mathrm{s}
$$

This flow rate of the portable tubular filter pipe is smaller than the flow rate of the aeration/sedimentation tank $(2.67 \mathrm{x}$ $\left.10^{-4} \mathrm{~m} / \mathrm{s}\right)$.

Therefore, the size of the filter is adequate and thereby enabling the filter unit delivers the same amount of water as the hand pump.

\subsection{Sand Bed Depth}

One of the literatures [18] recommended a sand bed depth of $20 \mathrm{~cm}$ and effective sand size of $1.4 \mathrm{~mm}$. The sand bed depth was checked against breakthrough of floc through the bed by calculating the minimum depth required. The minimum depth of sand required to avoid breakthrough of floc is $13.5 \mathrm{~cm}$. Hence the sand depth used in this work is $15 \mathrm{~cm}(0.15 \mathrm{~m})$.

\subsection{Filtration Component Head Loss Calculations}

Darcy's law was then used to calculate the head loss in the filter as follows:

$$
\begin{array}{r}
\mathrm{Q}=\mathrm{k} \cdot \mathrm{A} \frac{\Delta \mathrm{h}}{\Delta \mathrm{L}} \\
\Delta \mathrm{h}=\frac{\mathrm{Q} \Delta \mathrm{L}}{\mathrm{K} \cdot \mathrm{A}}
\end{array}
$$

For design purposes and simplicity, the calculations were based on filter media consisting of one layer [design scenario is sand with grain size of $1.4 \mathrm{~mm}$ ] and L being the sand bed depth. The area, (A); the flow rate, $(Q)$ and hydraulic conductivity, (k).

With $\mathrm{A}=0.0479 \mathrm{~m}^{2}, \mathrm{Q}=2.67 \times 10^{-4} \mathrm{~m}^{3} / \mathrm{s}, \mathrm{k}=8 \times 10^{-5} \mathrm{~m}^{3}$ $/ \mathrm{s}$ and $\mathrm{L}=0.15 \mathrm{~m}$, the head loss is:

$$
\Delta \mathrm{h}=\frac{2.67 \times 10^{-4} \times 0.15}{1.67 \times 10^{-3} \times 0.0479}=0.5 \mathrm{~m}
$$

\subsection{Filter Volume Calculations}

For the effective working of the filter, a filter surface area of $0.0479 \mathrm{~m}^{2}$ is necessary to deliver filtered water at a rate of approximately $8 \times 10^{-5} \mathrm{~m}^{3} / \mathrm{s}$ assuming the guidelines on head and filter sand size/depth are adhered to. Given a head loss of $0.5 \mathrm{~m}$, the portable tubular filter pipe will be able to deliver treated water as follows:

$$
\text { Volume, } V=0.5 \mathrm{~m} \times 0.0479 \mathrm{~m}^{2}=0.024 \mathrm{~m}^{3}
$$

\subsection{Materials for the Proposed Tubular Filter Pipe Design}

The proposed tubular filter media design is to be constructed using available PVC materials from water treatment stores or shops produced locally. The use of locally available material is important to ensure that the construction of the filter system is of low cost. The filter media both sand and gravel can be sourced locally.

Available Materials

The materials used for the proposed tubular filter pipe design are as follows:

(i) 1 inch diameter Cylindrical PVC Pipe

(ii) 4 inches diameter Cylindrical PVC Pipe

(iii) 4 inches diameter Cylindrical PVC Pipe Union

(iv) 1 inch diameter pipe Unions

(v) 4 by 1 inches diameters PVC Pipe Reducer

(vi) PVC Tape

(vii) PVC Gum

(viii) PVC Bulb Valve

(ix) Filter Net

(x) Filter disc

(xi) Sand

(xii) Gravel

(xiii) Activated Carbon

The pictures of the materials used are shown from figure 4-15.

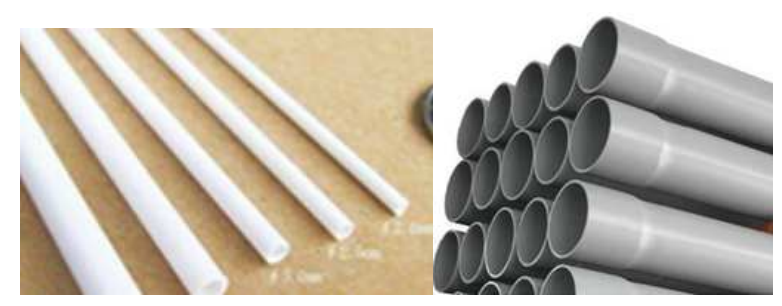

Figure 4. 1 inch and 4 inches diameters Cylindrical PVC pipes. 

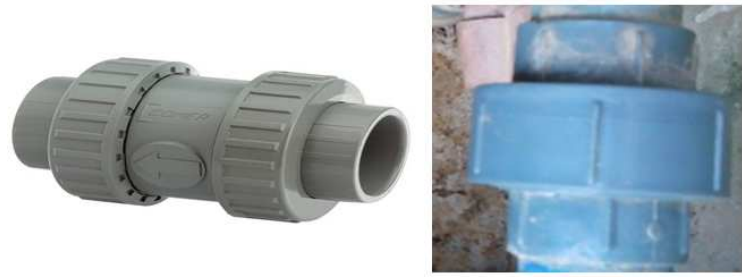

Figure 5. Cylindrical PVC pipe unions.
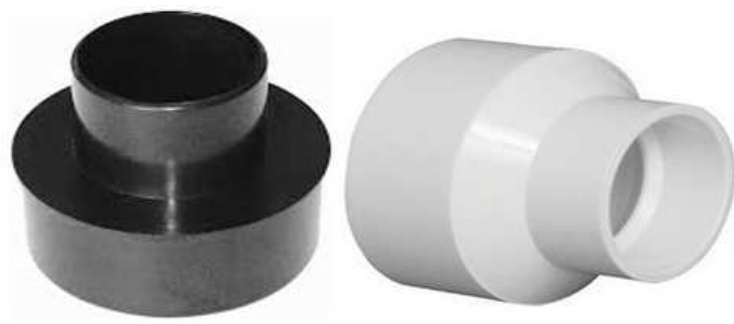

Figure 6. $4 \times 1$ inches diameters $P V C$ pipe reducers.

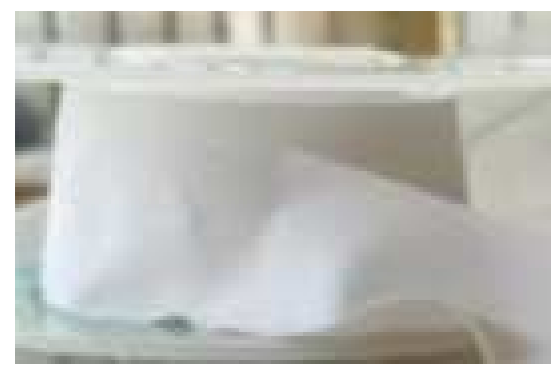

Figure 7. PVC Tape.

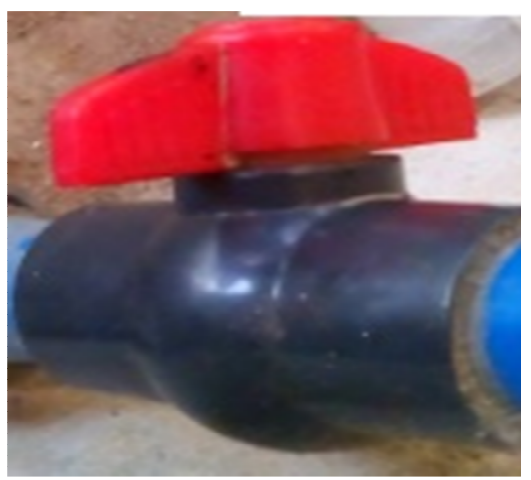

Figure 8. PVC Bulb Valve.

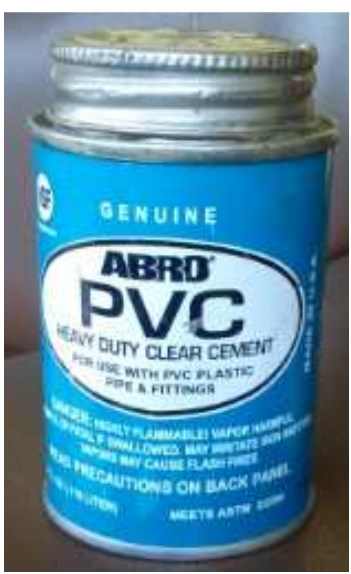

Figure 9. PVC Gum.

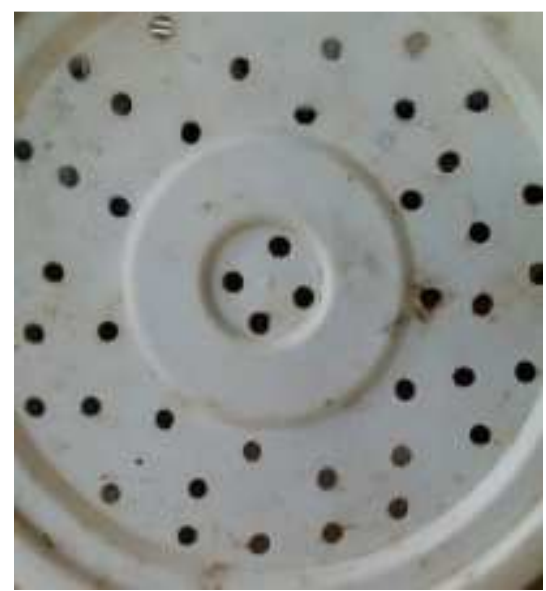

Figure 10. Filter disc.

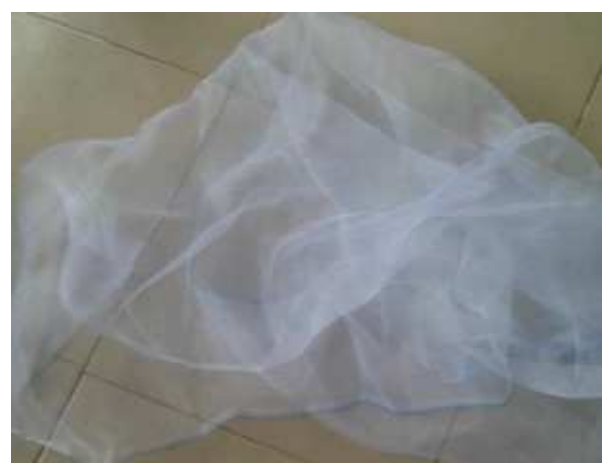

Figure 11. Filter net.

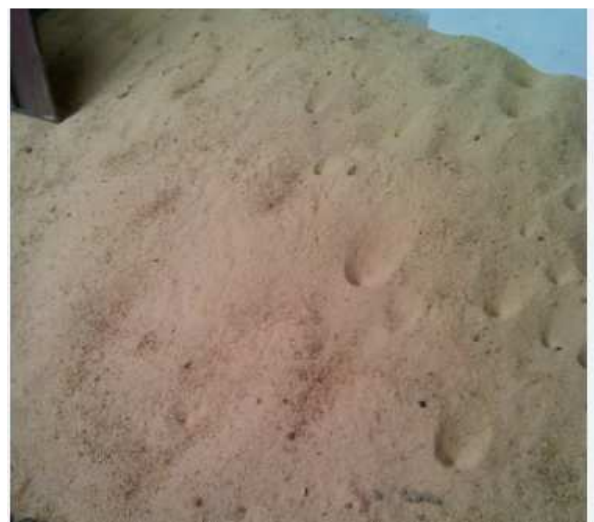

Figure 12. Fine Sand.

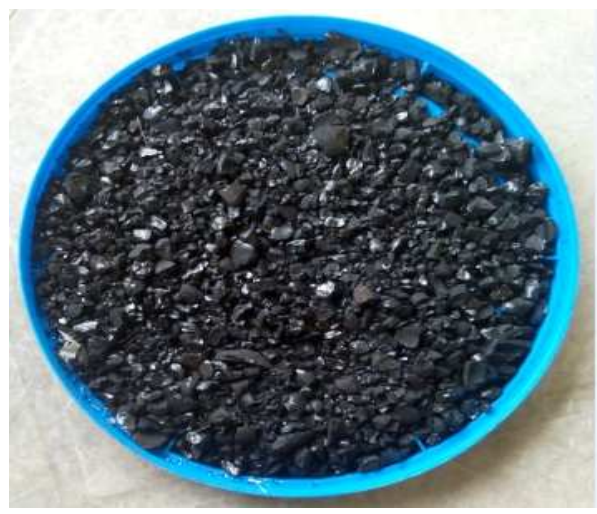

Figure 13. Activated carbon. 


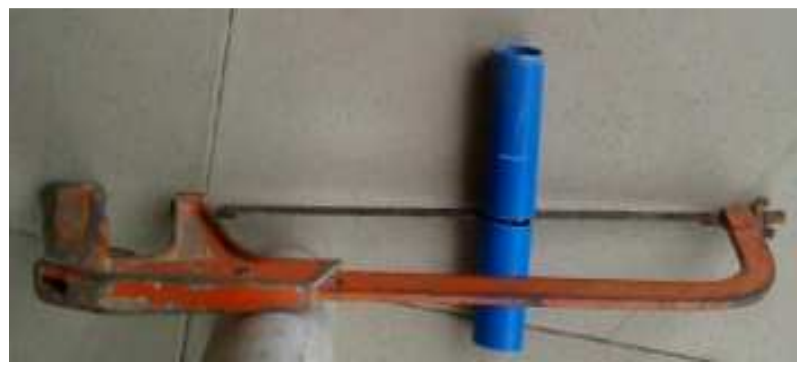

Figure 14. Hacksaw on a pipe.

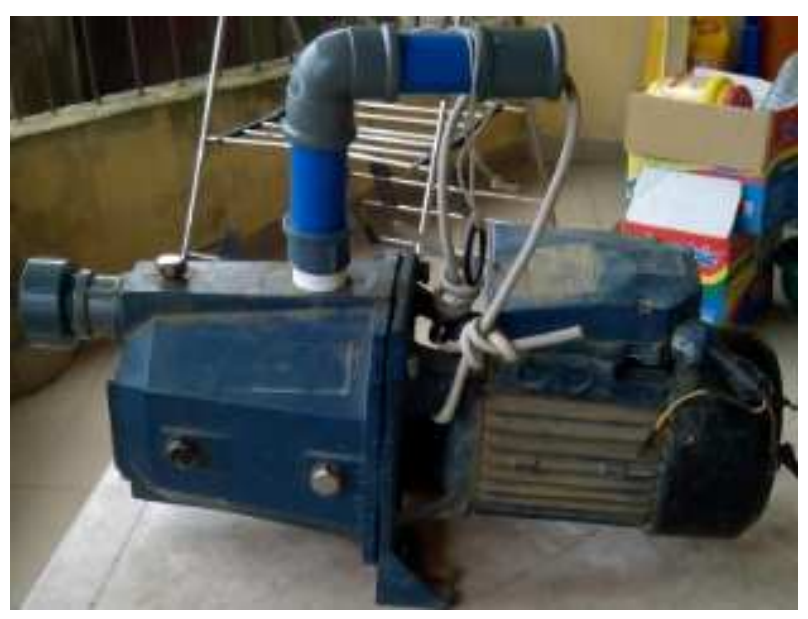

Figure 15. 1Hp water pump.

The design drawing for the proposed portable tubular filter media is shown in figure 16 .

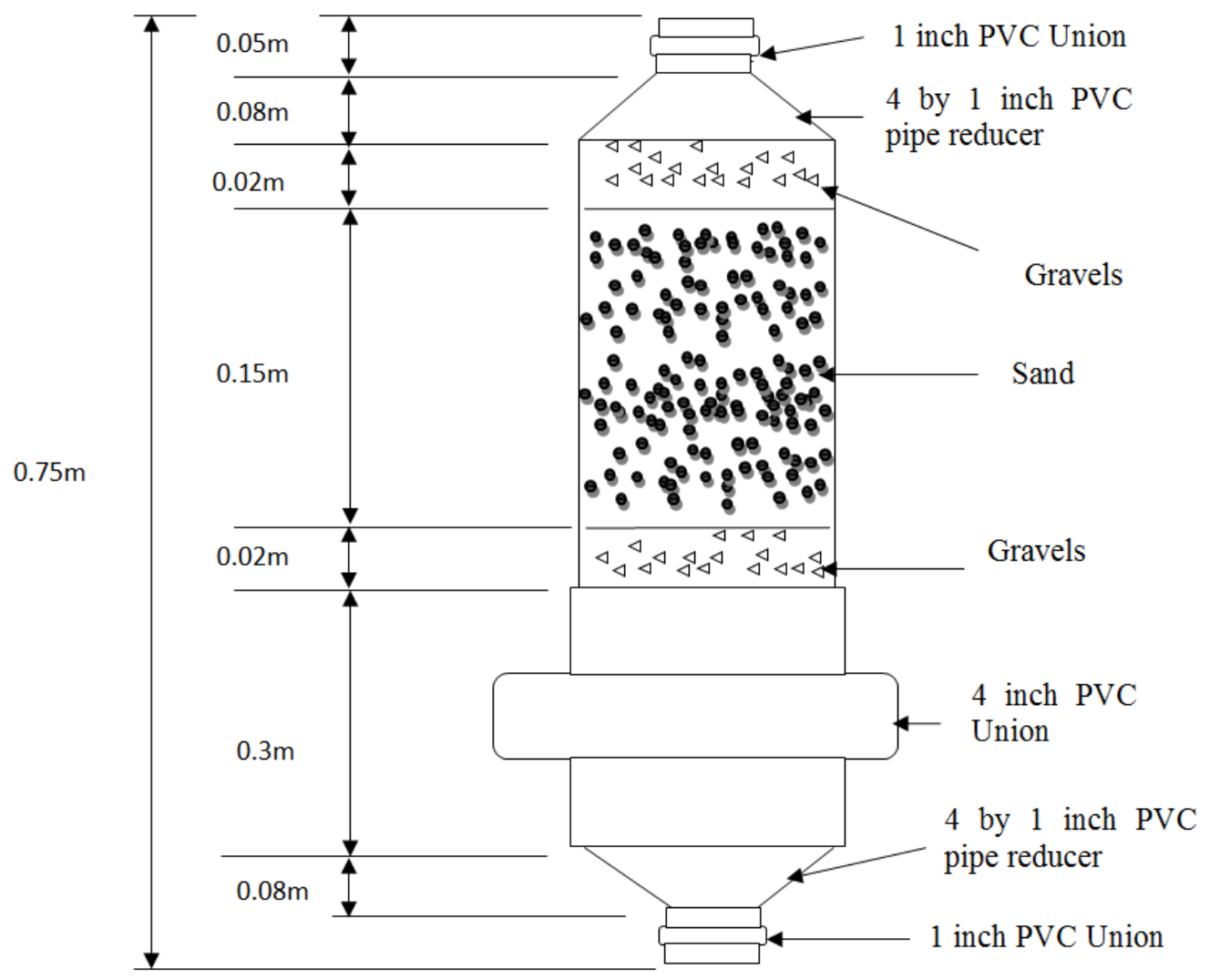

Figure 16. The design drawing of the Portable Tubular Filter Pipe. 


\section{Result}

\subsection{Groundwater Test and Result}

The purification process went through various tests to know the level of purity that has been achieved and the results were also compared with world Health organization (WHO) standards for water purification [20]. Table 1 shows the results of water samples from the borehole (raw groundwater).

Table 1. Results from raw groundwater sample.

\begin{tabular}{llll}
\hline $\mathbf{S} / \mathbf{N}$ & Parameters & P/C Analysis & WHO Standard \\
\hline 1 & General Appearance & Not clear with particles & \\
2 & Taste & Objectionable & Unobjectionable \\
3 & Odor & Objectionable & Unobjectionable \\
4 & Temperature & $30^{\circ} \mathrm{C}$ & Ambient \\
5 & Turbidity & 2.91 & 5 \\
6 & $\mathrm{P}^{\mathrm{H}}$ Value & 6.02 & $6.5-8.5$ \\
7 & Colour & Brown & 100 \\
8 & Total Hardness & $123.40(\mathrm{mg} / \mathrm{l})$ & 200 \\
9 & Total Alkalinity & 41.06 & 0.4 \\
10 & Total iron & 1.22 & 1000 \\
11 & Total Dissolved solid & 118.03 & $\mathrm{NTU}$ \\
12 & Total solid & 130.04 & $\mathrm{Mg} / 1$ \\
13 & Total suspended solid & 12.01 & $\mathrm{Mg} / 1$ \\
14 & Chloride & 0.00 & 25 \\
15 & Calcium $\left(\mathrm{ca}{ }^{2+}\right)$ & 10.42 & 25 \\
\hline
\end{tabular}

\subsection{Purified Water (Without the Use of the Portable Tubular Filter Pipe) Test and Result}

The purified water was also tested in the laboratory to know if it meets up with 'WHO' standard of purified water [20]. Table 2 shows the outcome of the results.

Table 2. Results from Treated groundwater sample.

\begin{tabular}{|c|c|c|c|c|}
\hline $\mathbf{S} / \mathbf{N}$ & Parameters & P/C Analysis & WHO Standard (maximum permit) & Unit \\
\hline 1 & General Appearance & Clear & Clear & \\
\hline 2 & Taste & Unobjectionable & Unobjectionable & \\
\hline 3 & Odor & Unobjectionable & Unobjectionable & \\
\hline 4 & Temperature & $25^{\circ} \mathrm{C}$ & Ambient & ${ }^{\circ}$ Celsius \\
\hline 5 & Turbidity & 0.00 & 5 & NTU \\
\hline 6 & $\mathrm{P}^{\mathrm{H}}$ Value & 7.48 & $6.5-8.5$ & \\
\hline 7 & Colour & Colourless & 15 & $\mathrm{TCU}$ \\
\hline 9 & Total Alkalinity & 13.06 & 200 & $\mathrm{Mg} / 1$ \\
\hline 10 & Total iron & 0.01 & 0.3 & $\mathrm{Mg} / 1$ \\
\hline 11 & Total Dissolved solid & 15.07 & 1000 & $\mathrm{Mg} / \mathrm{l}$ \\
\hline 12 & Total solid & 10.40 & 500 & $\mathrm{Mg} / \mathrm{l}$ \\
\hline 13 & Total suspended solid & 0.01 & 25 & $\mathrm{Mg} / 1$ \\
\hline 14 & Chloride & 6.33 & 250 & $\mathrm{Mg} / \mathrm{l}$ \\
\hline 15 & Calcium $\left(\mathrm{ca}^{2+}\right)$ & 10.42 & 75 & $\mathrm{Mg} / 1$ \\
\hline
\end{tabular}

\subsection{Purified Water (with the Use of the Portable Tubular Filter Pipe) Test and Result}

The final stage of this work was carried out with the use of the portable tubular filter pipe and the result coupled together is shown in the table 3 .

Table 3. Results from Treated groundwater sample with the portable tubular filter pipe.

\begin{tabular}{|c|c|c|c|c|}
\hline $\mathbf{S} / \mathbf{N}$ & Parameters & P/C Analysis & WHO Standard (maximum permit) & Unit \\
\hline 1 & General Appearance & Clear & Clear & \\
\hline 2 & Taste & Unobjectionable & Unobjectionable & \\
\hline 3 & Odor & Unobjectionable & Unobjectionable & \\
\hline 4 & Temperature & $25^{\circ} \mathrm{C}$ & Ambient & ${ }^{\circ}$ Celsius \\
\hline 5 & Turbidity & 0.00 & 5 & NTU \\
\hline 6 & $\mathrm{P}^{\mathrm{H}}$ Value & 7.00 & $6.5-8.5$ & \\
\hline 7 & Colour & Colourless & 15 & TCU \\
\hline 8 & Total Hardness & $11.22(\mathrm{mg} / \mathrm{l})$ & 100 & $\mathrm{Mg} / 1$ \\
\hline
\end{tabular}




\begin{tabular}{lllll}
\hline S/N & Parameters & P/C Analysis & WHO Standard (maximum permit) & Unit \\
\hline 9 & Total Alkalinity & 10.06 & 200 & $\mathrm{Mg} / 1$ \\
10 & Total iron & 0.01 & 0.3 & $\mathrm{Mg} / 1$ \\
11 & Total Dissolved solid & 10.07 & 1000 & $\mathrm{Mg} / 1$ \\
12 & Total solid & 5.40 & 500 & $\mathrm{Mg} / 1$ \\
13 & Total suspended solid & 0.01 & 25 & $\mathrm{Mg} / 1$ \\
14 & Chloride & 5.33 & 250 & $\mathrm{Mg} / 1$ \\
15 & Calcium $\left(\mathrm{ca}^{2+}\right)$ & 9.42 & 75 & $\mathrm{Mg} / 1$ \\
\hline
\end{tabular}

\section{Conclusion and Discussion}

Table 1 shows the results of water samples from the borehole (raw groundwater). Table 2 shows the outcome of the results after treatment but without the Portable Tubular Filter Pipe. Table 3 contains the result of the purification system with the Portable Tubular Filter Pipe. The Portable Tubular Filter Pipe from the study shows that it could be used for purifying borehole water without a complex purification system or it could be used with a given purification system to make borehole water clean for a long time. It is also very clear as one compare and study the results from the tables 1-3 that the quality of the treated water with the Portable Tubular Filter Pipe show an improvement. More study will be done and reported in the next work for how long it will take for the Portable Tubular Filter Pipe to be cleaned or renewed.

\section{References}

[1] Adekunle A. A. and Adejuyigbe S. B Fabrication of Plastic Water Filter and Testing with Slow Sand Filtration Method. The Pacific Journal of Science and Technology, Volume 13, Number 1, 2012, Pp. 122-132.

[2] Bilge Alpaslan Kocamemi. Department of Environmental Engineering Istanbul, Marmara University, Turkey. Retrieved on 09/10/2019 fromwww.chp_12_Pressurefilters.pdf, 2019.

[3] Cecen, F. Activated carbon and waste water treatment. Retrieved on the19/01/2018 from [https://www.researchgate.net/publication/255714291], 2011.

[4] Chauhan Y. P. and Talib M. I. Design of Laboratory Scale Packed bed column for adsorption of phenol on to modified coal fly ash (MCFA). International Journal of Science, Engineering and Technology Research (IJSETR) Volume 6, Issue 4, ISSN, 2017, 2278-7798.

[5] Custodio, E. Trends in groundwater pollution: loss of groundwater quality and related services (eds). Retrieved on 28/12/2017 from [https://en.m.wikipedia.org/wiki/Groundwater_pollution], 2013.

[6] Dagim Abera Shigut, Geremew Liknew, Dejene Disasa Irge and Tanweer Ahmad. Assessment of physico-chemical quality of borehole and spring water sources supplied to Robe Town, Oromia region, Ethiopia, Applied Water Science, March 2017, Volume, 7, Issue 1, 2017, pp 155-164.

[7] Edet, A. E. Groundwater Quality Assessment in parts of Eastern Niger Delta. Nigeria. Environ. Geol.; 22 (1), 1993, 41-46.

[8] Etu-Efeotor, J. O and Akpokogje. E. G. Aquifer systems of the
Niger Delta: Journal of Mining and Geology, 1990, pp 279-285.

[9] Fawell, J., Bailey, K., Clinton, J, Dahi, E. Fluoride in drinking water. Retrieved on the 19/01/2018 from [https://en.m.wikipedia.org/wiki/Groundwater_pollution], 2006.

[10] Gleick, P. H. Water in crisis: A guide to the world's fresh water resources. Oxford University press, 1993, Pp 13-14.

[11] Harrison L. D., Brunner K. M., and Hecker W. C. A combined packed-bed friction factor equation: extension to higher Reynolds number with wall effects, AIChE J., 59, No. 3, 201, 703-706.

[12] John M. C. Weaver, Lisa Cave, and Siep Talma A. Groundwater Sampling, Groundwater Sciences, $2^{\text {nd }}$ Edition, CSIR, South Africa WRC Report No TT 303/07, March 2007, $1-205$.

[13] Kulshreshtha, S. N. A Global outlook for water Resources to the year 2025. Retrieved on 09/10/2019 from www.Global_outlook_for_water_resources_pdf, 1998.

[14] McCabe W. E., Smith J. C., and Harriott P. Unit Operations of Chemical Engineering, McGraw Hill, New York, 2001.

[15] Muna Y. Abdul - Ahad. Design Criteria of an Activated Carbon Bed for Dechlorination of Water. Iraqi Journal of Chemical and Petroleum Engineering, Vol. 9 No. 4, 2008, 4149.

[16] Noel Bourke, Gerry Carty, Matt Crowe and Marion Lambert. Water Treatment Manuals filtration, Published by the Environmental Protection Agency, Ireland, IFC. C Environmental Protection Agency, 1995, PP 1-80.

[17] Perry R. H., Green D. W, and Maloney J. O. Perry's Chemical Engineers Handbook, 7th Edition. McGraw-Hill, New York, 1997.

[18] Schmoll O., Howard G., Chilton G. Protecting Groundwater for Health: Managing the Quality of Drinking-water by World Health Organization (WHO). Retrieved on the 19/01/2018 from [https://en.m.wikipedia.org/wiki/Groundwater_pollution/Mana ging quality of drinking water. pdf], 2006.

[19] Shankar Subramanian R. Flow through Packed and Fluidized Beds, Department of Chemical and Biomolecular Engineering Clarkson University. Retrieved on 22/09/2019 from www.Flow_through_packed_fluidized_bed.Pdf, 2019.

[20] Stephen Siwila, Chopa Chota, Kumbu Yambani, Dingase Sampa, Amon Siangalichi, Niza Ndawa and Gabriel Tambwe. Design of a small scale iron and manganese removal system for Copperbelt University Borehole water. J Environ Geol, 1 (1), 2017, 24-30.

[21] Taonameso S., Mudau L. S., Traoré A. N., Potgieter N.. Borehole Water: A Potential Health Risk to Rural Communities in South Africa, Water Supply, 19 (1): 2019, 128-136. 
[22] WJS Van der Merwe. Analysis of flow through cylindrical packed beds with small cylinder diameter to particle diameter ratios. Dissertation submitted in fulfilment of the requirements for the degree Master in Nuclear Engineering at the Potchefstroom Campus of the North-West University, Retrieved on 22/09/2019 from www.van_der_merwe_WJS_Take.Pdf, 2019.

[23] WHO. "World Health Organization Guidelines for Drinking Water Quality". Vol 1, WHO: The Hague: Netherlands, 2006.
[24] Yousuo Digieneni, Igbani, Sunday and Raphael Tari Samuel. Design of a Portable Tubular Filter Pipe for Borehole Water Purification Systems, Department of Chemical Engineering, Niger Delta University, P. M. B 071 Yenagoa, Bayelsa State of Nigeria (Sent for Publication in Journal of Engineering and Applied Scientific Research, Cenresin Publications, Minna, Niger State, Nigeria), 2019. 